\title{
The Academic Archivist's Fear of Popular Music
}

\section{By Brock Silversides}

\section{Abstract}

This talk, delivered at the CAML Conference in Ottawa on June 4, 2015, examines a number of reasons for the reluctance of academic archivists/Special Collection librarians to acquire popular music fonds/collections. Arguments are put forward that popular music is an excellent indicator of the concerns of society and changes in culture, that it is worthy of scholarly research, and that as research trends are changing to incorporate popular music, so too should the collecting focus of music archivists/librarians.

Within the world of Canadian academic archives and special collections, there has long been a reluctance to acquire full and comprehensive archives of popular culture. This has, unfortunately, also been true in the field of academic music archives. Other fields are changing: literary archives, film archives, broadcast archives...they all seem to have overcome their hesitation to collect popular works - such as pulp fiction, sci-fi, sit-coms, the less-than-stellar "reality" programs, even soap operas and commercials - as well as the archives of their creators.

However there are still numerous music archivists who will only acquire archival collections relating to so-called "serious" music, sometimes referred to as "erudite" or even "art" music. Generally that means classical or experimental music. The archives of jazz - because that genre appears to straddle both the serious and the popular, and is seen as complex - are slowly but steadily gaining in respectability. But popular music - that is up in the air. It still has not made it onto the Top 10 charts of many academic archives.

By popular music then, I mean rock, blues, folk, country, metal, grunge, roots, soul, rap/urban, rockabilly, punk, and many more genres. They are without doubt legitimate genres: they have recognized structures, traditions, ideologies, and aesthetics. They have hierarchies for composers, performers, even record labels. Each has a canon of their finest works. They have

Brock Silversides is Director of the University of Toronto Media Commons.

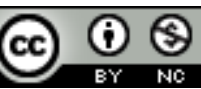

This work is licensed under a Creative Commons Attribution-NonCommercial 4.0 International License. 
critics, thoughtful analysts, and historians. They are already being examined by musicologists and cultural philosophers and documentarians. They have dedicated audiences, have notable legacies, and even have time on their side. For example rock is almost 60 years old, and folk, blues and country go back considerably further.

But there continues to be a bias against - perhaps even a fear of - popular music in academic archives and special collections. We all know it's there, even though many do their best to deny it. It is usually passive in nature, and many archivists (or more likely the managers of archives) do not try to put it into words - for some explaining their aversion to it somehow dignifies something that is not to be dignified.

More frustrating - it generally remains unsaid and unwritten. I have yet to hear tales of any spoken directives, or see any written collections policy or collection strategy that explicitly states that popular music is to be ignored. But - it is still happening.

The following information has not come from a structured survey or poll. It is the result of informal observation and is anecdotal in nature, but I believe still has merit. There are eight main reasons for the reluctance to collect popular music material that I have been able to squeeze out of archival colleagues. And these eight are a combination of personal pre-judgment as well as real operational issues:

1. There is a negative judgment about the relative importance of popular music - the idea that it is faddish and ephemeral, that it is derivative, repetitive, lightweight, meaningless, created by people with limited musical ability who cannot even read musical notation, appealing only to teenagers and the unsophisticated, and way too simple to deserve serious attention.

2. There is a negative judgment that popular music is not really an art - it is just a business that happens to incorporate a kind of music - and it is a sordid business at that.

3. There is a negative judgment about the content of the music - that it deals with radical politics, sex, drugs, violence, cheating and misogyny - all the baser desires - and that subjects like that are not worth dignifying by retaining for posterity.

4. There is a negative judgment about the people involved in the popular music scene. Constant generalizations are made that the musicians are immature slackers, thugs, stupid crackheads and drunks, that managers are criminally dishonest, that record companies have ties to organized crime and only care about sales, not the quality of the music, that broadcasters lack integrity and are still open to payola, etc. It seems as if everybody connected to the industry is assumed to be involved in bad behaviour of 
some kind. The activities of ne'er-do-wells like this - again - do not deserve to be kept for posterity. And they really do not deserve a tax credit!

5. Although the conception of popular music is that it is simple, the few who have ventured into a popular music archive quickly see that it can be a very complex activity with many different types of documents. There is a lack of specialized knowledge about what to keep within a potential archival offering to get maximum research value, and thus other types of collections which are more easily grasped get more favourable attention.

6. There are usually current and complicated rights issues surrounding popular music, and many archivists simply do not want to deal with them.

7. There are genuine and sometimes high costs associated with popular music collections arrangement and description, playback machinery, storage, dubbing and digitizing.

8. And finally - the biggest one of all. There are very real fears for the reputation of the institution in which one works, and fears for one's personal and professional reputation, if they are seen as collecting what many consider non-academic "disposable garbage."

This talk will examine these judgments point by point, counter some of them, stress that we archivists and managers need a serious reality check, touch on some new research trends in popular music, and generally put forward arguments for valuing and acquiring popular music archives.

1. Importance: Of course some popular music is simple and inane - there is no argument there - but by no means is it all simplistic and unintelligent. It runs along an extremely long continuum. And a huge proportion is very sophisticated, progressive, experimental, and groundbreaking. Some popular music is created and aimed at teenagers. There is just as much if not more - created for other age groups. Popular music has appealed, and continues to appeal, to the widest of demographics. And most musical creators have a habit of growing and evolving along with the audiences.

Does popular music follow or set trends? Most definitely it can do both, and that can be one of its strengths - immediate and ongoing relevance to cultural changes. However if there is ultimately no substance, it will fade away. Fortunately there is a large segment of popular music that always rises above the fads, and becomes timeless.

Archives - hopefully - are supposed to acquire material that reflects the work of all types of creators and all segments of society. Popular music plays an exceptionally important role in the 
lives of a large percentage of us. It always has. It has been with us since the beginning of time every culture that we know of has had its own music. It is also ubiquitous - it is on the radio, on the television, in commercials, in movie soundtracks, on telephone ringtones, in video games, and on countless online sites. It is in elevators, grocery stores, malls, restaurants, bars, waiting rooms, washrooms, churches and pretty well all public places. It is at political rallies, at public sports events, and fairs.

And with the upsurge in the use of personal listening devices - it is literally everywhere. You probably could not get away from music any more, even if you wanted to. It is a part of high culture, middle culture and low culture - a part of every level of society. It reflects almost everything that people are concerned with - issues of the day, politics, work, play, relationships, what is hip, what is not, societal changes, etc.

Pardon the cliché - but popular music is the soundtrack to most people's lives now - and has been for several generations. It is such a huge part of everybody's life that it cannot be written off a as distraction or a frill. How can popular music archives NOT be considered one of the most important series of documents to be saved as part of the historical record!

Make no mistake - popular music primary source material is crucial for any degree of understanding of our times. As for whether the work is good in terms of creativity, originality and quality - that's another question. Some obviously is - some is not. Some is popular or critically received now - some is not, but may be ahead of its time and will be seen as influential and important in decades to come. It is not always possible to make that determination until after that passage of time - and perhaps that is best left to the musicologists and music historians. A better question for the archivist is whether a set of archival documents is representative of its time or has perceived future value, whether it has or is affecting society, whether it sheds light on the activities of its creator(s), and if research clientele is needing it for their work.

2. Commerciality: The second hesitation on the part of some music archivists is that popular music has been, and still is, created to sell - that it is not created for the art of music itself, and is somehow a lesser form of creative activity. That too is a generalization. There is a considerable amount of popular music that is created where the performers are following their own artistic growth, and are not actually concerned if it sells in the millions.

But yes - generally speaking - popular music is a business. However - does the making of money just apply to popular music? I would argue that any kind of music that is written or performed for a paying audience, or put on record or broadcast has been at least partially created to sell. Most classical musicians had to cultivate rich and sometimes unenlightened 
patrons so they could keep going. Many had to alter compositions, perhaps include notes or sections that were not artistically valid, just to please their patrons and keep the subsidies flowing. In our times many orchestral players earn a large proportion of their living from playing on commercials or jingles, or in television and film soundtracks. Is this an inherently shameful action? Does this render them less worthy of respect, or of archiving?

Like all creators, musicians have to make a living - so the relationship between art and commerce is always going to be a consideration. Why do some archivists feel they can pass judgment on this? Why do they not embrace the reality of both art and commerce, and collect archival documentation that reflects the intersection of the two?

3. Personal Judgment: Some archivists (and especially older archives managers) simply do not like popular music. It can be loud, jarring, aggressive, fast, primitive - and the lyrics can be immature, earthy, provocative, impertinent, uneducated, anti-establishment, angry, and at times, downright rude. That is neither good nor bad - it just is. It still speaks to many people, and even the unpleasantness reflects a part of society at a given time. It is real life.

But this is also a massively one-sided assessment, for popular music can be as elevated as it is lowly. Undoubtedly the biggest themes in popular music have proven to be the yearning for and appreciation of romance, love, peace, equality, freedom, tolerance, human rights, concern for the environment, and an ideal world. These are topics that - more often than not - require a degree of intelligence and sensitivity. And popular music itself can be soft, mellifluous, relaxing, and occasionally even majestic. Thus it is never "best practice" for archivists or their managers to make decisions based on what they personally like or dislike - what they find pleasant or unpleasant.

4. Bad Behaviour: There is no doubt that some of the people involved in the music business are or have been less-than-respectable. Immature, irritating, egotistical, entitled, drug-fuelled, selfdestructive, bad behaviour is undoubtedly present within the popular music scene - sometimes even boastfully so. But is substance abuse, loose morals and bad behaviour the monopoly of popular musicians? Clearly it is not.

Two famous classical music heavyweights - Franz Liszt and Niccolo Paganini - are examples to be considered. Liszt did not gain respect until late in life in the 1850 s. For much of his younger period he was dismissed as a "superficial composer of brilliant trifles." He loudly and offensively proclaimed his anti-monarchical and revolutionary sentiments to the immense irritation of the establishment. And of course he had long hair, and was a womanizer almost beyond control including with married women, and with Lola Montez, who was a mistress (we might call her a groupie) to anyone who was anyone in Europe at the time. 
Paganini was truly the equivalent of a rock star. He was thin, pale, sickly and exceptionally dissolute - especially when on tour in the 1820s. He gambled, he drank, and really liked women! He played with such volume and intensity that audiences would become crazed. And like bluesman Robert Johnson in the 1930s - Paganini was suspected in his day of making a deal with the devil for his obvious talent. That notoriety was not necessarily seen as negative. Oh, he also had syphilis.

How many of the truly innovative, even great, jazz musicians were high for most of their lives? Charlie Parker, Miles Davis, John Coltrane, Sonny Rollins, Chet Baker - all were serious heroin addicts. And marijuana and cocaine have always been a constant in the jazz scene. Cab Calloway sang "Reefer Man" and Ella Fitzgerald sang "Wacky Dust"...and why do you think it is called the herbal "jazz" cigarette? If a previously unknown archival collection pertaining to any of the above was offered, do you think it would be refused by an archivist? I don't think so.

All this to say that bad behaviour and substance abuse has been a part of all music from all eras. But it too is still an overused stereotype. The majority of participants in the creation of popular music are mature, responsible people with a considerable work ethic. If they were not, they would not be in the business for long - they would have no staying power, and in the end no enduring impact or influence. And if a moral personality, polite behaviour, and clean record were serious criteria for the collecting of archives of creative people of any kind - be it writers, actors, academics, or artists - I suggest our shelves would be very bare.

5. Complexity: Even though archivists may think of popular music as simplistic, they usually catch on quickly enough and realize that its creation and dissemination can be extremely complicated. The popular music community is made up of many related and interlocking participants - composers, lyricists, musicians, producers, engineers, recording studios, managers, booking agents, record companies, concert promoters, music publishers, collective rights societies, club owners, festival coordinators, road managers, entertainment lawyers, photographers, videographers, documentary filmmakers, graphic artists, record stores, online music vendors, reviewers and critics, music magazines, bloggers, instrument makers, broadcasters, DJs and VJs, music colleges and music teachers, and the various industry organizations.

All of these individuals, organizations and companies generate archival material that tends to overlap and complement material from others. And, after going through some kind of thoughtful selection process, much of that material deserves to be kept in order to reconstruct an accurate picture of popular music as a creative activity and as an industry, as well as to give insight into changing technology and how that, in turn, affects both creativity and commerce. 
Not only are there many potential sources for archival popular music collections, but those collections can be quite voluminous and diverse in nature. There are so many types of documents that possess prime research value:

For textual - there are contracts (recording, management, concert, etc.), lyric sheets, scores and charts, royalty statements, production files, press release and kits, profiles/interviews, reviews, radio charts, promotional materials, business and marketing plans, scrapbooks, newsletters, correspondence, book drafts, etc.

For audio - there are composing tapes, rehearsals, demos, studio multitracks, various mixes, alternate takes, outtakes, test pressings, acetates, commercially pressed discs, live concerts, radio programs which can be performances or interviews

For video - meaning music videos, or television and film performances or commercials - there can be camera original film or field tapes, various edits from rough cuts to fine cuts, masters or release prints

For graphic arts - there can be advertising, posters, original artwork, album/CD cover art and mockups, promotional photographs, etc.

In one way or another, ALL these types of documents - whether analog or digital -are important as a total record of a creator's activities to create and disseminate their work. But an archivist has to have an informed idea of how it all works, how they relate to each other, and how they could be of use to a researcher.

6. Rights Issues: Rights issues in popular music - which is usually current enough to still be covered by statutes and legal agreements - is a complication that many archivists and archival managers just do not want to deal with. We all know of institutions that insist if they acquire a collection, then all the rights must come with it. That sounds good - like the wrapping up of loose ends - and theoretically lets them think they have full control over the material. But it is also unrealistic and naïve.

Copyright is a huge issue for sound recordings, both as a physical entity - and for its content. Most audio documents are usually the sophisticated combination of many people's creative contributions - the musicians performing of course, but also the producers, composers, lyricists, engineers, even software developers, etc. And they might either be independent contractors or all be staff employees of a producer or record company or broadcaster. Record companies and media companies get taken over, merge, go bankrupt, sell masters to publishers or back to the artists - there are so many complications. 
Each of the contributions (especially before 1998 - the year of the first big copyright amendments in Canada) can possibly be copyrighted - and under different categories. Each category can have differing and simultaneous terms of copyright which can run for differing periods of time. Other rights thrown into the mix could include publication rights, distribution rights, licensing rights, broadcast transmission rights, mechanical rights, synchronization rights, moral rights, crown copyright, etc.

This complexity and layering of rights sometimes means that - even if they wanted to - a donor may not even be able to sign over all rights to an archival institution. Thus, it is difficult though certainly not impossible - to determine the complete rights package. I realize that many institutions do not have the time or money or legal expertise to do the necessary analysis. But that is no reason not to acquire this type of material. They can still be of tremendous research value. For a period of time, an institution may not be able to provide copies or post material on their website, but in time all material will enter the public domain.

7. Costs: There are indeed costs involved with popular music archives as there are for all archives. There is no gain in trying to downplay these. Professional cataloguing (for archivists arrangement and description) and physical care of popular music documents can be considerable. The description of musical documents takes specialized knowledge. The audiovisual formats in particular require knowledge of technical formats and production methods, and this will take special training. Learning about the rights issues will also take special training or - if the archival staff do not or cannot do it - consultation with an entertainment or copyright lawyer. That is also costly.

Most audio-visual formats are notoriously unstable due to their manufacture - companies have usually used the cheapest possible ingredients with no thoughts of longevity. They thus need environmentally-appropriate storage, and archival enclosures/sleeves/boxes to prolong their lifespans.

There are many formats of audio and video, and they are constantly being superseded and becoming obsolete. To access them, an institution needs to own or borrow or rent an assortment of current and non-current playback machines - both consumer and professional quality. If an archive decides to own and operate them, then they have to employ one or more technicians to run them properly and maintain them. This is particularly expensive.

Then there is the issue of dubbing and digitizing - whether in-house or outsourced, and hopefully in accordance with professional standards. It is usually more expensive than most people realize. These concerns all require an ongoing funding commitment - not a one-timeonly expenditure, and so for many archival managers it is a definite deterrent. 
8. Reputations: The question of the institutional, professional and personal reputations is unfortunately the most difficult to put into words, and the most difficult to counter. On a macro level, it would appear that Canadian society as a whole enjoys popular culture, makes it a part of their everyday life, but rarely sees it as having an enduring value. As a result they do not particularly want their tax dollars being put toward its preservation. As academic institutions rely to a great extent on the public purse, they have to be more careful than ever to not appear to be wasting the taxpayers' money.

Over and above this, there is, in some academic institutions, the odor of enduring elitism and snootiness amongst faculty who favour the study of "serious" music at the expense of all others. The managers of college and university archives and special collections - those that make the acquisition decisions and have the greatest influence with the upper, upper administration - have traditionally catered to these faculty. The result is an extraordinarily lopsided set of holdings, Ivory-towered in their obscurity, which see low or non-existent usage.

However, in the new world order in which archives find themselves - we have to, in many cases, justify our existence with usage numbers as a statistical means of demonstrating that collections are being accessed by the academic community and/or general public. I am not recommending for a minute that we do not continue to acquire "serious" music archival material because so few researchers use them - but to focus exclusively on them is a losing proposition. As one can see just from some of the interesting sessions at this conference, research trends are changing. There is a new breed of academics, younger, and more open to and actively teaching - the history and influence of popular music.

Since 1979 - when Rob Bowman taught the very first popular music class at York - most Canadian universities have offered a growing number of courses on the topic, and a large number of masters and doctoral students are writing theses on popular music topics. A lightning quick look into the online "ProQuest Dissertations \& Theses" listing combining the terms (popular and music) gives thousands of hits. They give an idea of how much work is being done on issues such as the nationalizing force of song, music and commerce, regional histories of rock, basement bands and garage rock, rock journalism, popular music and class, the music recording process, music and marketing, music and cultural policy, music and feminism, popular music and digital shoplifting, Western Canadian music festivals - and more specifically on the music of Neil Young, Joni Mitchell, Leonard Cohen, Blue Rodeo, Rush, Celine Dion, Shania Twain, and on and on... Some of the most original, exciting and insightful cultural research is being done in this area. The field is wide open and appears to be expanding. 
There is clearly a corresponding need to acquire more non-serious music collections to service these researchers. As music archivists, we are not slightly behind the curve - we are decades behind the curve!

And finally we have to be aware that there is a professional undercurrent. Any increasing activity in the collecting of popular music might not necessarily be welcomed by fellow archivists and archival managers. As we try to bring them out of their comfort zone, they may think we are being immature and shallow like the music and the musicians they so dislike, and that we not taking our professional responsibilities as archivists seriously. There will also be some who will be of the opinion that we personally - especially if we actually enjoy acquiring popular music - cannot be taken seriously. That is usually not a problem for an established midcareer professional, but it could have a chilling effect on entry-level archivists.

To sum up then - in the end, most acquisition decisions made in archives are connected to the resources available, and to prevailing views as to what kind of archival material is acceptable to spend funding on. Funding is tight in all archives - and in many academic institutions is getting tighter. Priorities for acquisitions have to be made though, and in many cases decisions are made in accordance with what will meet with the general approval of funding bodies, management, and society at large. Unfortunately the knee-jerk reaction of too many stodgy conservative archival managers has been to put popular music at the bottom of the priority list as it seems to be one of the more difficult to make an argument for.

This approach may only serve to make academic music archives and special collections more irrelevant. If we want to acquire archival music collections that fairly represent what the majority of society have been influenced by and are still listening to, and which will be accessed and appreciated by an ever-increasing number of serious researchers, then I strongly recommend that we make every effort to put popular music into the priority list. We have to try to change the misconceptions of the nature and role of popular music in the minds of archivists and institutional managers, and engage with the real world of research - and the real world period. And we have to get the solid and loud support of music faculty and students, and other researchers.

There should be no further doubt that popular music is a legitimate, and even essential, collecting objective. Its archival documentation can and does provide important research materials on artistic activity, on many aspects of social and cultural history, on the development of an important and large multi-faceted entertainment industry, and on a constantly changing technology. 